\title{
Antimicrobial efficacy of mixtures of silver nanoparticles and polyhydric alcohols against health-promoting bacteria
}

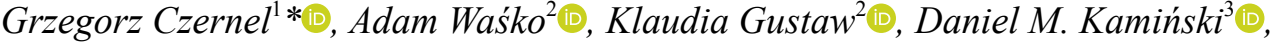 \\ Arkadiusz P. Matwijczuk ${ }^{1}{ }^{(}$, Aldona Nowicka ${ }^{4}$, Alicja S. Matwijczuk ${ }^{1}$, Tomasz Oniszczuk ${ }^{5}$, \\ Marta Arczewska ${ }^{1}$, and Dariusz Karcz ${ }^{6}$ D \\ ${ }^{1}$ Department of Biophysics, University of Life Sciences in Lublin, Akademicka 13, 20-950, Lublin, Poland \\ ${ }^{2}$ Department of Biotechnology, Microbiology and Human Nutrition, University of Life Sciences in Lublin, Skromna 8, \\ 20-704 Lublin, Poland \\ ${ }^{3}$ Department of Crystallography, Faculty of Chemistry, Maria Curie-Skłodowska University, Maria Curie Skłodowska Square 3, \\ 20-031 Lublin, Poland \\ ${ }^{4}$ Analytical Laboratory, Faculty of Chemistry, Maria Curie-Skłodowska University, Maria Curie Skłodowska Square 3, \\ 20-031 Lublin, Poland \\ ${ }^{5}$ Department of Thermal Technology and Food Process Engineering, University of Life Sciences in Lublin, Głęboka 31, \\ 20-612 Lublin, Poland \\ ${ }^{6}$ Department of Analytical Chemistry (C1), Faculty of Chemical Engineering and Technology, Kraków Technical University, \\ Warszawska 24, 31-155 Kraków, Poland
}

Received October 29, 2018; accepted July 8, 2019

Abstract. In the present study, the effectiveness of a mixture of silver nanoparticles with polyhydric alcohols (glycerol, erythritol, mannitol and xylitol) against six species of healthpromoting bacteria have been examined. Synthesis of silver nanoparticles was carried out using trisodium citrate as the reducing and stabilizing agent. The nanoparticles were characterized by electronic absorption, scanning electron microscopy and powder $\mathrm{X}$-ray diffraction measurements. Electronic absorption spectrum revealed high uniform of synthesized nanoparticles. Practically no aggregation was observed when nanoparticles were mixed with polyhydric alcohols, suggesting weak interaction between ingredients of the mixture. Spherical silver nanoparticles, as depicted by scanning electron microscopy, were found to have diameters in the range of 10 to $30 \mathrm{~nm}$; mean diameter was $18 \pm 4 \mathrm{~nm}$. The $\mathrm{X}$-ray diffraction pattern of the prepared samples indicated the face-centred cubic crystalline structure of the metallic silver nanoparticles. In biological study, quite interesting protective effect of polyalcohols on the growth inhibition of health-promoting bacteria by silver nanoparticles was observed. The most substantial protective effect of the tested silver nanoparticles-polyalcohol mixtures was estimated for B. bifidum, L. paraplantarum, and $L$. phamnosus species.

Keyw ord s: silver nanoparticles, antimicrobial effect, healthpromoting bacteria, polyhydric alcohols, packaging

*Corresponding author e-mail: grzegorz.czernel@up.lublin.pl

\section{INTRODUCTION}

The safe production and storage of food is associated with a number of challenges with respect to controlling microbiological hazards and pathogens (Kulak et al., 2018; Nawrocka and Cieśla, 2013; Ognik et al., 2016). In recent years silver nanoparticles (AgNPs) have been used as antimicrobial agents for improving food safety especially in the field of food packaging (Bikiaris, and Triantafyllidis 2013). On the other hand, some authors consider that glycerol, and other polyalcohols are the best plasticizers to use for the production of food packaging (Chocyk et al., 2015; Oniszczuk et al., 2016; Toxqui-Teránet al., 2018). Increasingly, many consumer products with food packaging contain AgNPs. For that reason, it is possible for the nanoparticles to migrate into food matrices. However, it is well known that nanoparticles featuring novel chemical and physical properties that differ from normal macroparticles of the same composition may interact with food and with the human body after consumption (He and Hwang, 2016). Due to their small size, there may be an increased risk of nanoparticles penetrating human cells and causing cytotoxicity. For example, AgNPs may cross the cellular barrier

(C) 2019 Institute of Agrophysics, Polish Academy of Sciences 
thereby leading to the formation of free radicals in the tissues and eventually causing oxidative damage to the cells and tissues (Pradhan et al., 2015). The oxidative stressdependent mechanism of toxicity of AgNPs described above have led to the conclusion that silver nanoparticles are genotoxic and even carcinogenic.

Other important recent studies have evaluated the potential effect of AgNPs on intestinal microflora after ingestion (Bergin and Witzmann, 2013; Javurek et al., 2017). Karavolos and Holban (2016) reported the effect of dietary AgNPs, which preferentially kills microbiome components and, thus, causes the induction of dysbiosis. The connection between dysbiosis and disease has been well documented (Karavolos, 2015). However, at present, the mechanisms of action of silver nanoparticles against gut microbiota are not yet clearly understood. Nevertheless, some authors have described AgNPs binding to cell membranes that include sulphur-containing proteins and a sugar-phosphate backbone of DNA. As a result of this binding activity, the nanoparticles preferentially attack the respiratory chain, they also influence cell division, which may finally lead to cell death (Rai et al., 2009).The human intestinal microbiota comprises bacteria, fungi, viruses and archaea, which form a complex ecosystem and have a close relationship with the host. The Lactobacillus and Bifidobacterium genera constitute the majority of beneficial bacteria and have been used as probiotic dietary supplements to improve the activities of digestion, metabolism, and the immune system (Degnan, 2008). Apart from the positive effect of probiotics on general well-being, there are several particular clinical symptoms or conditions that are reported to be beneficially affected by the use of specific probiotics. Such conditions include diarrhoea, gastroenteritis, inflammatory bowel disease, irritable bowel syndrome, Crohn's disease, and the alleviation of the symptoms of lactose intolerance (Degnan, 2008). As yet, there have been investigations regarding the antibacterial effects of AgNPs mainly using pathogenic bacteria; only a few studies have been carried out with beneficial bacteria (Gornicka et al., 2014; Tyagi et al., 2016). The increasing usage of AgNPs in connection with different types of plasticizers such as polyalcohols suggest that studies concerning the influence of AgNPs activity on a wider range of bacteria are necessary.

In the current study, we investigated the antimicrobial potential of AgNPs toward health-promoting bacteria based on the example of Lactobacillus, Bifidobacterium, which inhabit the human intestine and are commonly used as probiotic dietary supplements. We conducted research to identify polyalcohols, which may have a protective effect on probiotic bacteria, with a view to their application in the food industry.

\section{MATERIAL AND METHODS}

Silver nitrate $\left(\mathrm{AgNO}_{3}\right)$ trisodium citrate $\left(\mathrm{C}_{6} \mathrm{H}_{5} \mathrm{O}_{7} \mathrm{Na}_{3}\right)$, sodium hydroxide $\mathrm{NaOH}$ and hydrochloric acid $\mathrm{HCl}$ (Sigma Aldrich) of analytical grade purity, were used as starting materials without further purification. Polyhydric alcohols (glycerol, erythritol, mannitol and xylitol) were purchased from Sigma-Aldrich. In all of the experiments double distilled water was used. The silver nanoparticles were prepared by using a chemical reduction method according to the description of Lee and Meisel (1982). Typically, $50 \mathrm{~mL}$ of $10^{-3} \mathrm{M} \mathrm{AgNO}_{3}$ aqueous solution was heated up to the boiling temperature and the solution was stirred vigorously during the synthesis process. While stirring, a solution of $1 \%$ sodium citrate $(5 \mathrm{~mL})$ was added. The solution was kept at the boiling point for $10 \mathrm{~min}$ until the colloids changed colour. The solution was heated continuously until the colour changes were apparent (pale green). At that point, heat is no longer applied and the solution is stirred continuously until it cools to room temperature. The size of the synthesized AgNPs was controlled by the $\mathrm{pH}$ of the solution during synthesis. After that, the AgNPs solution was mixed with polyhydric alcohols in order to obtain $20 \%\left(\mathrm{~m} \mathrm{~m}^{-1}\right)$ mixtures, which were used in the experiment.

Electronic absorption spectra at desired dilutions of silver colloids were recorded using a spectrophotometer Cary 300 Bio (Varian) equipped with a thermostatted cuvette holder with a $6 \times 6$ multicell Peltier block. The temperature was controlled with a thermocouple probe (Cary Series II from Varian) placed directly in the sample. The UV-Vis spectra were recorded from a base solution, which had been diluted tenfold.

The size and morphology of the silver nanoparticles were determined by SEM. After washing in double distilled water and ultrasonication, the samples were placed on circular aluminium stubs, slightly dried and transferred into the chamber of a scanning electron microscope Quanta 3D FEG (FEI). Micrographs were taken using an ETD detector, at an accelerating voltage of $30 \mathrm{kV}$. The AgNPs diameter was measured using Nis-Elements Advanced Research software. Particle distribution was derived from a histogram considering 500 particles.

Colloidal AgNPs were deposited on a glass plate and dried overnight under vacuum. After that, the dry nanoparticles were analysed using a powder X-ray diffraction technique with an Empyrean (PANalytical) diffractometer with a $\mathrm{Cu}$ anode as a source for $\mathrm{CuK} \alpha \mathrm{x}$-ray radiation $(\lambda=$ $1.5406 \AA$ ). All samples were measured over a $2 \theta$ range of 2 to $90^{\circ}$ with a step size of $0.013^{\circ}$ and an exposition time per step of $1 \mathrm{~s}$. The approximated mean size of the spherical nanoparticles was calculated according to the well-known Scherrer equation with the Scherrer shape constant of 0.9 (Scherrer, 1918). The peak broadening was $\sim 0.03^{\circ}$. 
A statistical analysis was carried out with the use of the Origin 9.0 software. For the UV-Vis spectra, the full width at half maximum (FWHM) value, was calculated from the fits of the Voight function to every UV-Vis peak. The SEM histogram was described by the bigaussian function with a different width for the left and right shoulder. Data are presented as a mean and standard deviation $( \pm \mathrm{SD})$. The standard deviation was calculated from the confidence interval of $24 \mathrm{~nm}$, which consisted of more than $99 \%( \pm 3 \sigma)$ of the measured particles. For the left shoulder $\sigma \mathrm{l}=2.7 \mathrm{~nm}$ and for the right shoulder $\sigma \mathrm{r}=5.3 \mathrm{~nm}$. For the X-ray diffraction of the FWHM, the average diameter and standard deviation was calculated from the fits of the Voight function to the three peaks $\{111\},\{200\}$ and $\{220\}$ (Table 1).

Bifidobacterium adolescentis 15706, B. bifidum 29521, B. breve 15700 , Lactobacillus paraplantarum 700211, obtained from American Type Culture Collection (Rockville, MD, USA); L. rhamnosus, from Biomed Serum and Vaccine Production Plant Ltd., (Lublin, Poland), were used for this study. The specific test strains of Llactobacilli and Bbifidobacteria were selected because they are either already established as probiotics and are used in pharmaceutical products or they have potential probiotic properties. The Lactobacillus and Bifidobacterium cultures were maintained at $-80^{\circ} \mathrm{C}$ in MRS Broth (BTL, Lódź, Poland) containing 20\% (wt/vol) glycerol. Cultivation tests were performed in a medium based on MRS Broth supplemented with $0.05 \%$ L-cysteine $\mathrm{HCl}$.

The antibacterial properties of AgNPs in the presence of polyalcohols were determined using a Bioscreen $\mathrm{C}$ system (Labsystem, Helsinki, Finland). After a 24-h incubation, the bacterial cultures were centrifuged and removed from the medium. The bacterial cells were suspended in physiological saline, and an optical density of 0.5 was set at $600 \mathrm{~nm}$. The analysed bacteria were grown in MRS with $10 \mu \mathrm{g} \mathrm{mL}^{-1}$ of AgNPs and $2 \%$ of glycerol, erythritol, mannitol and xylitol. $350 \mu \mathrm{L}$ of the media were transferred onto honeycomb 100-well plates in triplicate, and the wells were inoculated with $50 \mu \mathrm{L}$ of bacterial suspension. The experiment was performed under anaerobic conditions by measuring the OD $600 \mathrm{~nm}$ every 2 for $48 \mathrm{~h}$. Growth curve parameters (max specific growth rate, lag time, doubling time, etc.) were determined using the PYTHON script according to Hoeflinger et al. (2017).

A statistical analysis was carried out with use of Origin 9.0 software. For UV-Vis spectra, the full width at half maximum (FWHM) value, was calculated from the fits of the Voight function to every UV-Vis peak. The SEM histogram was described by the bigaussian function with a different width for the left and right shoulder. Data are presented as a mean and standard deviation $( \pm \mathrm{SD})$. The standard deviation was calculated from the confidence interval of $24 \mathrm{~nm}$, which consisted of more than $99 \%( \pm 3 \sigma)$ of the measured particles. For the left shoulder $\sigma \mathrm{l}=2.7 \mathrm{~nm}$ and for the right shoulder or $=5.3 \mathrm{~nm}$. For the X-ray diffraction of FWHM,
Table 1. X-ray size distribution of AgNPs in different crystallographic directions

\begin{tabular}{lccc}
\hline Reflection & $\{111\}$ & $\{200\}$ & $\{220\}$ \\
\hline Related diameter $(\mathrm{nm})$ & $12.7 \pm 0.1$ & $9.1 \pm 0.1$ & $14.1 \pm 0.1$ \\
\hline
\end{tabular}

average diameter and standard deviation was calculated from the fits of the Voight function to the three peaks $\{111\}$, $\{200\}$ and $\{220\}$ (Table 1).

\section{RESULTS AND DISCUSSION}

The synthesized AgNPs were characterized by electronic absorption spectroscopy UV-Vis, scanning electron microscopy and powder X-ray diffraction. Figure 1 presents electronic absorption spectra with a narrow absorption peak at $398 \mathrm{~nm}$ due to the surface plasmon resonance (SPR) of AgNPs (black line). In the case of the mixture of AgNPs with polyhydric alcohols, a small bathochromic shift (2 nm) was observed (Fig.1 coloured lines). The shift towards a longer wavelength (red shift) was observed for the AgNPs-polyalcohol mixture and indicated an increased particle size and increased state of aggregation compared to the pure nanoparticles. This effect may be explained by the adsorption of polyhydric alcohols on the surface of the nanoparticles. Based on UV-Vis spectra and the methodology described in the work (Paramelle et al., 2014 ), the size and concentration of nanoparticles in a solution were estimated to be $\mathrm{D}=16 \mathrm{~nm}$ and $\mathrm{c}=2.7 \times 10^{-9} \mathrm{M}$. The values of full width at half maximum (FWHM) are $57 \pm 1 \mathrm{~nm}$ for AgNPs and $65 \pm 1 \mathrm{~nm}$ for mixtures of silver nanoparticles with polyhydric alcohols which indicates a highly uniform size of AgNPs, these results are in accordance with previous research (Wang et al., 1999). These findings are consistent with SEM measurements giving a diameter distribution ranging from 10 to $32 \mathrm{~nm}$ (calculated for spherical AgNPs only) (Fig. 2). The mean diameter of AgNPs from the SEM experiment is $18 \pm 4 \mathrm{~nm}$. As may be observed in Fig. 3, the distribution is not symmetrical which may

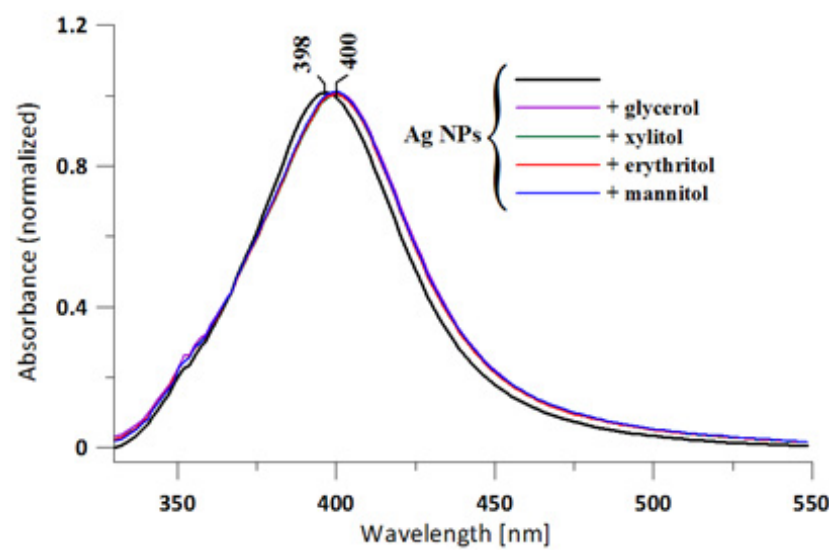

Fig. 1. The UV-visible absorption spectra of the colloidal solution of AgNPs (black line, $398 \mathrm{~nm}$ ) and a mixture of AgNPs with all polyhydric alcohols (coloured lines, $400 \mathrm{~nm}$ ). 

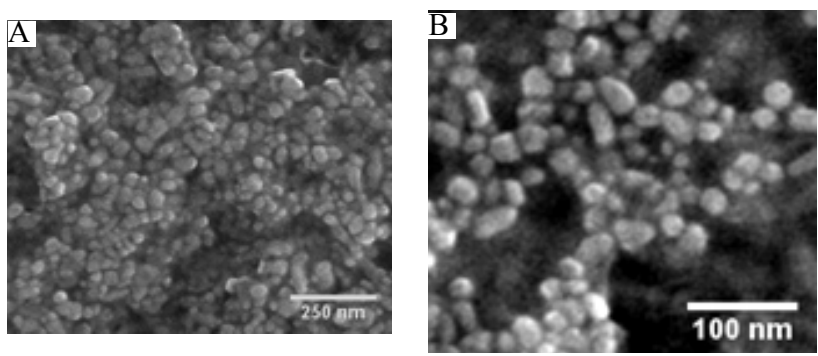

Fig. 2.Taken at 50000 (A) and at 100000 (B) magnification SEM micrographs of AgNPs.

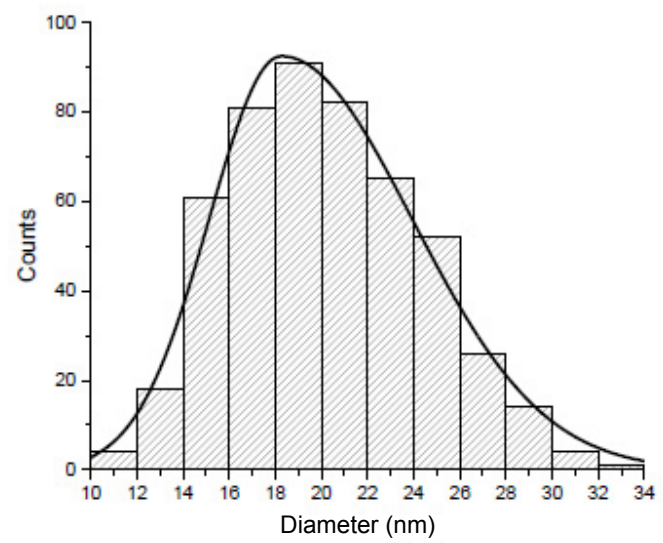

Fig. 3. Histogram of the pure AgNPs size distribution from SEM measurement. The black line shows a bigaussian function fit to the particle-diameter distribution.

be partially explained by the aggregation mechanism at the reaction stage. Such an effect has already been observed in other experiments (Kostiv et al., 2015).The distribution is well described by a bigaussian curve with width 3.1(3) and 5.7(3) for the left and right shoulder of the bigaussian function, respectively. It should be noted that the size of the nanoparticles from the SEM experiment are usually overestimated due to particle charging (they look more swollen) and coating (Kim, 2010).

As a complementary method used to estimate the size of the AgNPs, dry nanoparticles were measured with powder XRD (Fig. 4). Based on a broadening effect of the peaks, a mean particle size was estimated using the Scherrer equation, see Table 1 . The average diameter calculated from $\mathrm{XRD}$ is $12 \pm 3 \mathrm{~nm}$, however, the differences in sizes between the different crystallographic directions may indicate cubes with rounded corners rather than spheres of AgNPs.

As may be expected, the diameter obtained in the X-ray diffraction experiment is smaller than the one from the SEM experiment because the X-ray method underestimates the particle size. This effect is caused by several factors, which were precisely explained in the work of Singh (2005). Additionally, the size of the coherently scattered domains is usually smaller than that of nanoparticles. However, taking into account the differences between the SEM and XRD techniques and the errors encountered, it

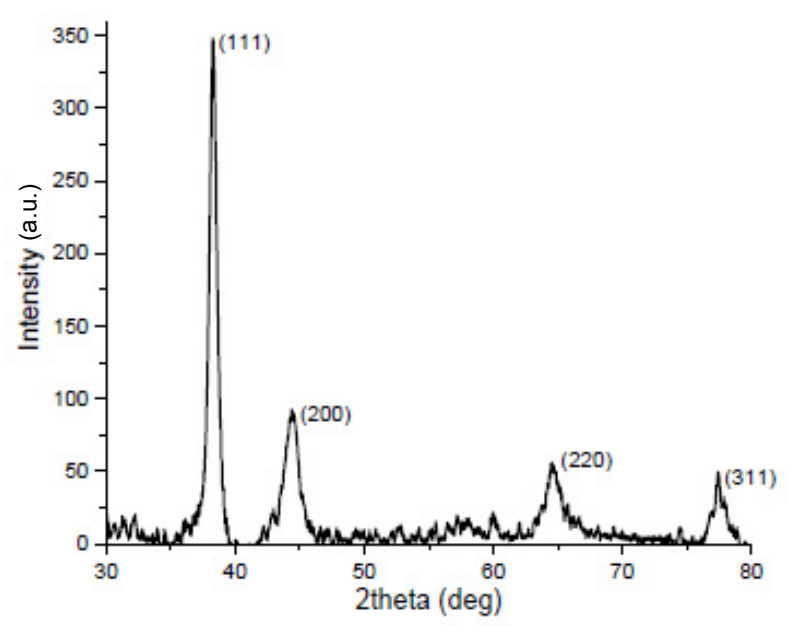

Fig. 4. Powder X-ray diffraction pattern of face-centred cubic dry AgNPs used in the experiment.

may be stated that the results are consistent. In this case, XRD determines the lowest and the SEM, the upper limit of the particle diameter.

In the electronic absorption spectra, no changes were observed that would indicate a change in size uniformity or aggregation of AgNPs induced by the addition of polyalcohols. The influence of polyalcohols on the characteristics of AgNPs were not studied using SEM and XRD due to the preparation methods, e.g. rinsing with deionized water followed by complete drying.

The major problem with using nanocomposites containing AgNPs is the great speed of the diffusion of nanomaterials, for example, the migration of AgNPs from plastic food containers amounted to $1.66-31.46 \mathrm{ng} \mathrm{cm}^{-2}$ (Echegoyen and Nerin, 2013). Most commonly, AgNPs are used in food packaging, they are added as an antimicrobial agent (E174) to beef, and serve to prevent water loss in the alginate gel coatings of carrots and asparagus (Kahru and Ivask, 2013). Some authors have reported that the leaching of $\mathrm{Ag}^{+}$ions from reusable food containers to food simulants in water was $5 \mathrm{n} \mathrm{cm}^{-2}$ over 10 days, polyethylene bags released $10 \mathrm{ng} \mathrm{cm}^{-2}$ after 10 days, and $34 \mathrm{ng} \mathrm{cm}^{-2}$ of $\mathrm{Ag}^{+}$ ions after using the same containers three times (Huang et al., 2011; Von Goetz et al., 2013). At present, different materials are employed in the production of nanocomposites containing of AgNPs. These materials are based on biopolymers, which often need the addition of a plasticizer to improve the flexibility of the material. Plasticizers are commonly employed as additives in the preparation of comestible films including the compounds that belong to the family of polyols, and some sugars with similar properties to polyols (Cao et al., 2009).

In this study, we explain the interaction of silver nanoparticles with polyols, which have a protective effect on health-promoting bacteria. In our study, all of the probiotic bacteria tested demonstrated considerable growth (i.e. 
Table 2. Growth parameters of Lb. rhamnosus, Lb. paraplantarum, B. adolescentis, B. breve, and B. bifidum

\begin{tabular}{|c|c|c|c|c|c|c|c|}
\hline Species & Medium & $\begin{array}{l}\text { Lag time } \\
\text { (hours) }\end{array}$ & $\begin{array}{c}\text { Max } \\
\text { specific } \\
\text { growth rate } \\
\left(\text { hours }^{-1}\right)\end{array}$ & $\begin{array}{l}\text { Doubling } \\
\text { time } \\
\text { (hours) }\end{array}$ & Max OD & Min OD & $\mathrm{R}^{2}$ \\
\hline \multirow[t]{6}{*}{ Lb. rhamnosus } & Control & 0.99 & 0.14 & 4.88 & 1.79 & 0.05 & 1.00 \\
\hline & AgNPs & 1.27 & 0.14 & 5.10 & 1.74 & 0.04 & 1.00 \\
\hline & $\mathrm{AgNPs}+\mathrm{E}$ & 1.13 & 0.13 & 5.36 & 1.76 & 0.05 & 1.00 \\
\hline & $\mathrm{AgNPs}+\mathrm{G}$ & 0.75 & 0.09 & 7.56 & 1.26 & 0.00 & 1.00 \\
\hline & $\mathrm{AgNPs}^{+\mathrm{K}}$ & 8.45 & 0.15 & 4.57 & 1.72 & 0.04 & 0.99 \\
\hline & $\mathrm{AgNPs}+\mathrm{M}$ & 4.11 & 0.20 & 3.44 & 1.73 & 0.04 & 1.00 \\
\hline \multirow[t]{6}{*}{ Lb. paraplantarum } & Control & 3.68 & 0.33 & 2.11 & 1.77 & 0.06 & 1.00 \\
\hline & AgNPs & 3.62 & 0.32 & 2.13 & 1.71 & 0.05 & 1.00 \\
\hline & $\mathrm{AgNPs}+\mathrm{E}$ & 3.79 & 0.31 & 2.25 & 1.71 & 0.05 & 1.00 \\
\hline & $\mathrm{AgNPs}+\mathrm{G}$ & 3.70 & 0.23 & 3.02 & 1.24 & -0.02 & 1.00 \\
\hline & $\mathrm{AgNPs}+\mathrm{K}$ & 3.26 & 0.22 & 3.11 & 1.70 & 0.06 & 1.00 \\
\hline & $\mathrm{AgNPs}+\mathrm{M}$ & 3.69 & 0.30 & 2.30 & 1.67 & 0.05 & 1.00 \\
\hline \multirow[t]{6}{*}{ B. adolescentis } & Control & 0.93 & 0.05 & 13.85 & 1.18 & 0.27 & 0.99 \\
\hline & AgNPs & 0.00 & 0.04 & 17.23 & 1.14 & 0.37 & 1.00 \\
\hline & AgNPs+E & 0.00 & 0.03 & 21.53 & 1.02 & 0.41 & 0.99 \\
\hline & $\mathrm{AgNPs}+\mathrm{G}$ & 0.00 & 0.04 & 18.11 & 1.11 & 0.38 & 1.00 \\
\hline & $\mathrm{AgNPs}+\mathrm{K}$ & 0.00 & 0.03 & 23.23 & 1.54 & 0.37 & 0.97 \\
\hline & $\mathrm{AgNPs}+\mathrm{M}$ & 0.00 & 0.04 & 15.61 & 1.08 & 0.39 & 1.00 \\
\hline \multirow[t]{6}{*}{ B. breve } & Control & 3.43 & 0.20 & 0.41 & 2.05 & 0.30 & 1.00 \\
\hline & AgNPs & 3.94 & 0.22 & 3.22 & 2.09 & 0.40 & 1.00 \\
\hline & $\mathrm{AgNPs}+\mathrm{E}$ & 4.32 & 0.22 & 3.12 & 2.06 & 0.39 & 1.00 \\
\hline & $\mathrm{AgNPs}+\mathrm{G}$ & 0.96 & 0.16 & 4.36 & 2.01 & 0.39 & 1.00 \\
\hline & $\mathrm{AgNPs}+\mathrm{K}$ & 0.00 & 0.04 & 16.53 & 1.87 & 0.38 & 0.92 \\
\hline & $\mathrm{AgNPs}+\mathrm{M}$ & 1.29 & 0.15 & 4.71 & 1.95 & 0.46 & 0.99 \\
\hline \multirow[t]{6}{*}{ B. bifidum } & Control & 0.35 & 0.16 & 4.37 & 2.00 & 1.08 & 1.00 \\
\hline & AgNPs & 5.54 & 0.26 & 2.68 & 2.02 & 0.36 & 1.00 \\
\hline & AgNPs+E & 5.96 & 0.25 & 2.73 & 2.01 & 0.36 & 1.00 \\
\hline & $\mathrm{AgNPs}+\mathrm{G}$ & 2.93 & 0.19 & 3.72 & 1.89 & 0.44 & 1.00 \\
\hline & AgNPs $+\mathrm{K}$ & 4.24 & 0.18 & 3.78 & 1.99 & 0.35 & 0.99 \\
\hline & $\mathrm{AgNPs}+\mathrm{M}$ & 5.57 & 0.24 & 2.86 & 1.98 & 0.34 & 1.00 \\
\hline
\end{tabular}

E - represents erythritol, G - glycerol, X - xylitol, M - mannitol in the mixture with AgNPs, respectively.

reached a final OD $600>1.0$ ) on MRS supplemented with glucose as a control (Table 2). Interestingly, in this study the concentration of silver nanoparticles at a level of $10 \mu \mathrm{g}$ $\mathrm{mL}^{-1}$ (about $16-18 \mathrm{~nm}$ ) had the best antibacterial properties only to the $B$. adolescentis 15706 . This concentration did not show any bactericidal effect against all five bacterial species (Table 2). Our results indicate the general dependency of the bacteriostatic effect of solutions of AgNPs used in this study. These results are consistent with the findings of Fröhlich and Fröhlich (2016) who reported that the toxicity of AgNPs among different gram-postive bacteria isolated from the human gut was between 1.5 and $120 \mu \mathrm{g}$ $\mathrm{mL}^{-1}$. Gornicka et al. (2014) described the weakest and significantly different inhibiting effect of AgNPs towards Lactobacillus and Bifidobacterium, which was proven for samples with a concentration of $0.25 \mu \mathrm{g} \mathrm{mL}^{-1}$. However, in our opinion, differences in the sensitivity of the tested bacteria may also be determined by the size of the AgNPs and the type of method used. Some authors have corroborated that the bactericidal effect of silver nanoparticles is 
size dependent (Rai et al., 2009). Most notably, this study also showed that nanoparticles smaller than $10 \mathrm{~nm}$ interact with bacteria and produce electronic effects, which enhance the reactivity of nanoparticles. Also, the size of the AgNPs will have an influence on the dissolution rate. Well dispersed nanoparticles will indeed have a higher surface of contact with the bacterial cells. A microculture method was used for the quantitative determination of the antibacterial activity of silver nanoparticles relative to health-promoting bacteria. The overall results indicated that in these methods the antibacterial activity of AgNPs depend on the concomitant release of $\mathrm{Ag}^{+}$ions. It may also be important for $\mathrm{AgNPs}$ to be oxidized in aqueous solutions resulting in the release of $\mathrm{Ag}^{+}$ions under acidic conditions (Xiu et al., 2012). Such acidic conditions are to be expected in the presence of $L$. paraplantarum 700211 and L. rhamnosus, as these bacteria produce large volumes of lactic acid as a metabolite.

The studies demonstrated the noteworthy protective effect of polyalcohols on the growth inhibition of health-promoting bacteria by silver nanoparticles. The more pronounced protective effects of the tested AgNPs were shown at lower B. bifidum 29521, L. paraplantarum
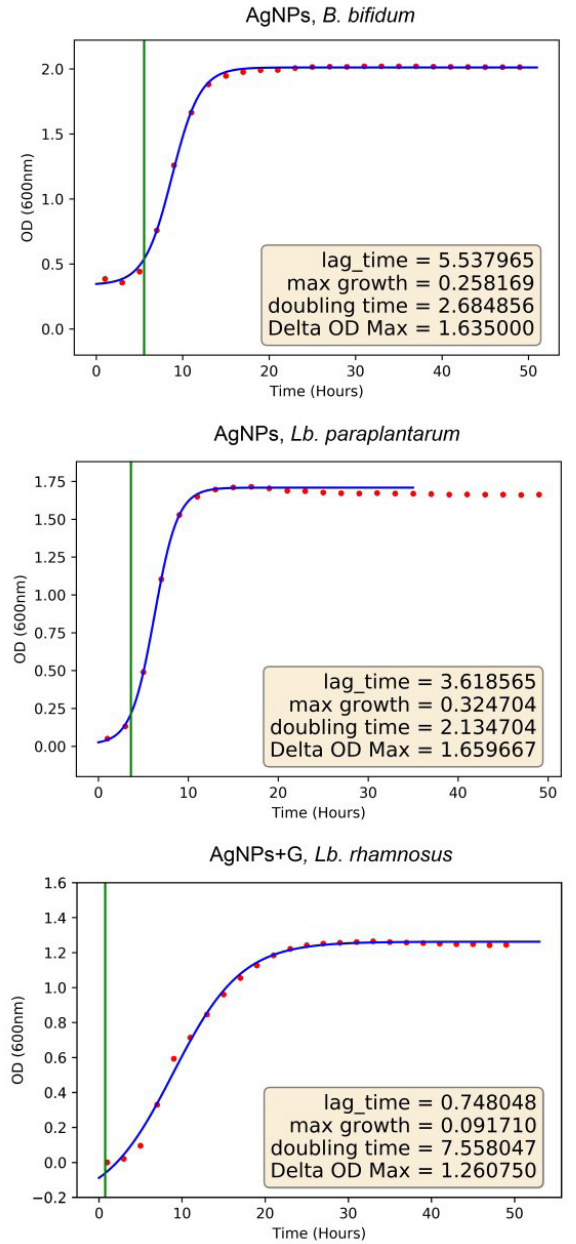

700211, and L. rhamnosus levels (Table 2 and Fig. 5). In the present study, all of the kinetic parameters of the growth curves (lag $t_{\min }$ time, max specific growth rate, etc.) the examined bacteria indicated that erythritol, xylitol, mannitol and glycerol could be used effectively in preventing the migration of AgNPs. A data set containing 30 bacterial growth curves was analysed with the regression analysis (RA) script and inspected visually. In both data sets, an $\mathrm{R}^{2}$ value $\geq 0.92$ was a reasonable cut-off between good and bad regressions. This effect may be explained by the probability of contacting the bacteria with silver nanoparticles. It should be noted that in the oligodynamic effect, $\mathrm{Ag}^{+}$ions may cause the irreversible aggregation of thiol- or aminebearing molecules (Le Ouay and Stellacci, 2015). They found that, the affinity of NPs for the surface of the bacterial cell depends on the $\zeta$-potential of the NPs (which in turn depends on the ionic strength of the solution). The polyols used in this study were hydrophilic with good solubility in water and effect of ionic strength of broth medium. Finally, the protective effects of polyalcohols, against the effects of AgNPs on health-promoting bacteria may be due to a combination of oxidation and oligodynamic mechanisms or by
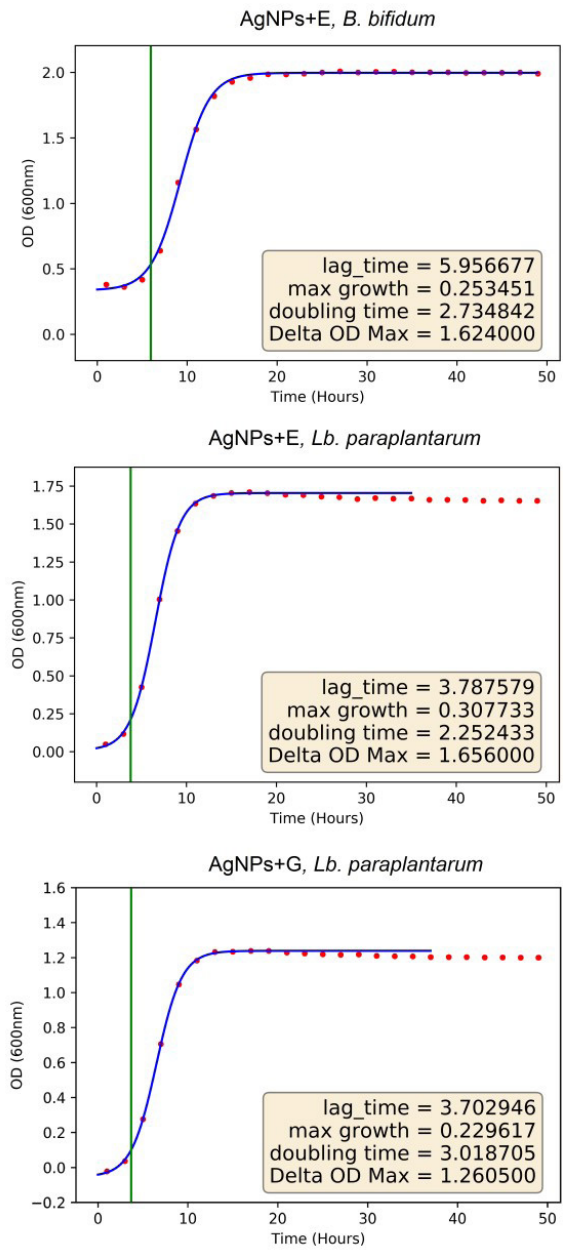

Fig. 5. Sample regression curves of selected data. All bacterial species grew better in the presence of polyhydric alcohols, growth parameters are higher with excellent regression. 
the formation of an additional layer around AgNPs similar to the one observed for lipids (Budziak et al., 2018).The protective effect could also be related to the polyol coating of the nanoparticles. This phenomenon is currently under investigation.

\section{CONCLUSIONS}

The addition of polyalcohols has a minor effect on the size, the aggregation process and uniformity of AgNPs.

Silver nanoparticles $(18 \pm 4 \mathrm{~nm})$ with a concentration at the level of $10 \mu \mathrm{g} \mathrm{mL}^{-1}$ showed antibacterial activity with only one species of bacteria (B. adolescentis 15706) from the six species of health-promoting bacteria tested.

Silver nanoparticles $(18 \pm 4 \mathrm{~nm})$ with a concentration at the level of $10 \mu \mathrm{g} \mathrm{mL}^{-1}$ had a variable antibacterial activity depending on the species of health-promoting bacteria tested.

Even the small addition of polyalcohols (2\%) played a protective role against the negative effects of AgNPs on health-promoting bacteria. This means that polyols may be promising plasticizers, which reduce the migration of AgNPs.

The benefit of the proposed use of polyalcohols is their low cost and safety as a nanocomposite, which is not source of $\mathrm{Ag}^{+}$ions.

The plasticizers described, may be applied in food technology and food packaging.

Conflict of interest: The Authors declare that they have no conflict of interest.

\section{REFERENCES}

Bergin I. L. and Witzmann F.A., 2013. Nanoparticle toxicity by the gastrointestinal route: evidence and knowledge gaps. Int. Biomedical Nanoscience Nanotechnology, 3, 163-210. https://doi.org/10.1504/ijbnn.2013.054515

Bikiaris D.N. and Triantafyllidis K.S., 2013. HDPE/Cu-nanofiber nanocomposites with enhanced antibacterial and oxygen barrier properties appropriate for food packaging applications. Materials Letters, 93, 1-4. https://doi.org/10.1016/j.matlet.2012.10.128

Budziak I., Arczewska M., Sachadyn-Król M., Matwijczuk A., Waśko A., Gagoś M., Terpiłowski K., and Kamiński D.M., 2018. Effect of polyols on the DMPC lipid monolayers and bilayers. BBA Biomembranes, 1860, 2166-2174. https://doi.org/10.1016/j.bbamem.2018.08.014

Cao N., Yang, X., and Fu Y., 2009. Effects of various plasticizers on mechanical and water vapor barrier properties of gelatin films. Food Hydrocolloids, 23: 729-735. https://doi.org/10.1016/j.foodhyd.2008.07.017

Chocyk D., Gladyszewska B., Ciupak A., Oniszczuk T., Mościcki L., and Rejak A., 2015. Influence of water addition on mechanical properties of thermoplastic starch foils. Int. Agrophys., 29, 267-275.

https://doi.org/10.1515/intag-2015-0031
Degnan F.H., 2008. The US Food and Drug Administration and Probiotics: Regulatory Categorization. Clinical Infectious and Disease, 46, 133-139. https://doi.org/10.1086/523324

Echegoyen Y. and Nerin C., 2013. Nanoparticle release from nano-silver antimicrobial food containers. Food Chem. Toxicol., 62, 16-22. https://doi.org/10.1016/j.fct.2013.08.014

Fröhlich E. and Fröhlich E., 2016. Cytotoxicity of nanoparticles contained in food on intestinal cells and the gut microbiota. Int. J. Molecular Sci., 17, 509. https://doi.org/10.3390/ijms17040509

Gornicka E., Mikiciuk J., Wrońska A., Szterk A., RachtanJanicka J., Rosiak E., and Mazur M., 2014. The influence of silver nanoparticles on fecal bacteria susceptibility. Digest J. Nanomaterials Biostructures, 9(1), 347-354.

He X. and Hwang H.M., 2016. Nanotechnology in food science: functionality, applicability, and safety assessment. J Food Drug Analysis, 24, 671-681. https://doi.org/10.1016/j. jfda.2016.06.001

Hoeflinger J.L., Hoeflinger D.E., and Miller M.J., 2017. A dynamic regression analysis tool for quantitative assessment of bacterial growth written in Python. J. Microbiol. Methods, 132: 83-85. https://doi.org/10.1016/j.mimet.2016.11.015

Huang Y., Chen S., Bing X., Gao C., Wang T., and Yuan B., 2011. Nanosilver migrated into food-simulating solutions from commercially available food fresh containers. Packaging Technol. Sci., 24, 291-297.

https://doi.org/10.1002/pts.938

Javurek A.B., Suresh D., Spollen W.G., Hart M.L., Hansen S.A., Ellersieck M.R., Bivens N.J., Givan S.A., Upendran A., and Kannan R., 2017. Gut dysbiosis and neurobehavioral alterations in rats exposed to silver nanoparticles. Sci. Reports, 7, 2822-2836. https://doi.org/10.1038/s41598-017-02880-0

Kahru A. and Ivask A., 2013. Mapping the dawn of nanoecotoxicological research. Accounts of Chemical Res., 46, 823833. https://doi.org/10.1021/ar3000212

Karavolos M., 2015. Host microbe interactions: A licence to interfere? Current Pharmaceutical Biotechnology, 16, 87-93. https://doi.org/10.2174/1389201015666141122205132

Karavolos M. and Holban A., 2016. Nanosized drug delivery systems in gastrointestinal targeting. Interactions with Microbiota. Pharmaceuticals, 9, 62. https://doi.org/10.3390/ph9040062

Kim K. H., Akase Z., Suzuki T., and Shindo D., 2010. Charging effects on SEM/SIM contrast of metal/insulator system in various metallic coating conditions. Materials Trans., 51(6), 1080-1083. https://doi.org/10.2320/matertrans.m2010034

Kostiv U., Šlouf M., Macková H., Zhigunov, A., Engstová H., Smolková K., Ježek P., and Horák D., 2015. Silica-coated up conversion lanthanide nanoparticles: The effect of crystal design on morphology, structure and optical properties. Beilstein J. Nanotechnol., 2290-2299.

https://doi.org/10.3762/bjnano.6.235

Kulak E., Ognik K., Stepniowska A., and Drazbo A., 2018. Effect of nanoparticles of silver on redox status and the accumulation of Ag in chicken tissues. J. Sci. Food Agric., 98, 4085-4096. https://doi.org/10.1002/jsfa.8925

Le Ouay B. and Stellacci F., 2015. Antibacterial activity of silver nanoparticles: A Surface Science Insight. Nano Today, 10, 339-354. https://doi.org/10.1016/j.nantod.2015.04.002 
Lee P. C. and Meisel D., 1982. Adsorption and Surface-Enhanced Raman of Dyes on Silver and Gold Sols. Journal of Physical Chemistry, 86, 3391-3395. https://doi.org/10.1021/j100214a025

Nawrocka A. and Cieśla J., 2013. Influence of silver nanoparticles on food components in wheat. Int. Agrophys., 27, 49-55. https://doi.org/10.2478/v10247-012-0067-x

Ognik K., Cholewinska E., Czech A., Kozlowski K., Wlazlo L., Nowakowicz-Debek B., Szlazak R., and Tutaj K., 2016. Effect of silver nanoparticles on the immune, redox, and lipid status of chicken blood. Czech J. Animal Sci., 61, 450461. https://doi.org/10.17221/80/2015-cjas

Oniszczuk T., Wójtowicz A., Mościcki L., Mitrus M., Kupryaniuk K. Kusz A., and Bartnik G., 2016. Effect of natural fibres on the mechanical properties of thermoplastic starch. Int. Agrophys., 30, 211-218. https://doi.org/10.1515/ intag-2015-0080

Paramelle D., Sadovoy A., Gorelik S., Free P., Hobleya J., and Fernig D.G., 2014. A rapid method to estimate the concentration of citrate capped silver nanoparticles from UV-visible light spectra. Analyst, 139, 4855-4861. https://doi.org/10.1039/c4an00978a

Pradhan N., Singh S., Ojha N., Shrivastava A., Barla A., and Rai V., 2015. Facets of nanotechnology as seen in food processing, packaging, and preservation industry. BioMed. Research Int., Article ID 365672, 17. https://doi.org/10.1155/2015/365672

Rai M., Yadav A., and Gade A., 2009. Silver nanoparticles as a new generation of antimicrobials. Biotechnol. Advances, 27, 76-83. https://doi.org/10.1016/j.biotechadv.2008.09.002
Singh A.K., 2005. Advanced X-ray Techniques in Research and Industry. IOS Press, US. ISBN print 978-1-58603-537-2

Scherrer P., 1918. Determination of the size and internal structure of colloidal particles using X-rays. Nachr. Ges. Wiss. Goettingen, Math-Phys K1. Vol. 1918, 98-100.

Toxqui-Terán A., Leyva-Porras C., Ángel Ruíz-Cabrera M., Cruz-Alcantar P., and Saavedra-Leos Z., 2018. Thermal study of polyols for the technological application as plasticizers in food industry. Polymers, 10, 467. https://doi.org/10.3390/polym10050467

Tyagi P.K., Mishra M., Khan N., Tyagi, S., and Sirohi S., 2016. Toxicological study of silver nanoparticles on gut microbial community probiotic. Environ. Nanotechnol., 5, 36-43. https://doi.org/10.1016/j.enmm.2016.01.003

Von Goetz N., Fabricius L., Glaus R., Weitbrecht V., Gunther, D., and Hungerbuhler K., 2013. Migration of silver from commercial plastic food containers and implications for consumer exposure assessment. Food Additives \& Contaminants Part A Chem. Anal. Control Expo. Risk Assess, 30, 612-620. https://doi.org/10.1080/19440049.2012.762693

Wang W., Chen X., and Efrima S., 1999. Silver nanoparticles capped by long-chain unsaturated carboxylates. J. Physical Chem., B, 103, 7238-7246. https://doi.org/10.1021/jp991101q

Xiu Z.M., Zhang Q.B., PuppalaH.L., Colvin V.L., and Alvarez P.J., 2012. Negligible particle-specific antibacterial activity of silver nanoparticles. Nano Letters, 12, 4271-4275. https://doi.org/10.1021/nl301934w 